\title{
Determination of prognosis of Philadelphia chromosome-negative myeloproliferative neoplasms with a simple clinical examination: Retrospective analysis of 71 patients in a single institution
}

\author{
SHINICHI ITO ${ }^{1}$, YUTAKA TSUTSUMI ${ }^{1}$, HIROYUKI OHIGASHI ${ }^{1}$, \\ SOUICHI SHIRATORI ${ }^{1,2}$ and TAKANORI TESHIMA ${ }^{2}$ \\ ${ }^{1}$ Department of Hematology, Hakodate Municipal Hospital, Hakodate, Hokkaido 041-8680; \\ ${ }^{2}$ Department of Hematology, Hokkaido University Graduate School of Medicine, Sapporo, Hokkaido 060-8638, Japan
}

Received February 26, 2015; Accepted September 18, 2015

DOI: $10.3892 / \mathrm{mco} .2015 .652$

\begin{abstract}
Philadelphia chromosome-negative myeloproliferative neoplasms (MPNs), including polycythemia vera (PV), essential thrombocytosis (ET) and primary myelofibrosis (PMF), are clonal hematopoietic diseases. A single-institution retrospective analysis was performed, including $71 \mathrm{MPN}$ patients diagnosed at the Hakodate Municipal Hospital between April, 2001 and April, 2014, and certain clinical characteristics were identified as effective prognostic factors. The patients were categorized by risk factor scoring based on age, number of abnormal blood cell lineages and splenomegaly at diagnosis, and the association between this categorization and prognosis was analyzed using a statistical procedure. The effect of Janus kinase 2 (JAK2) V617F mutation on prognosis was also investigated. The MPN patients were consolidated into three risk groups based on the margin of intergroup survival differences: i) Score 1-2 $(n=23)$, ii) score $3(n=24)$ and iii) score 4-5 $(\mathrm{n}=24)$. MPN patients with scores of 4 or 5 exhibited poorer overall survival (OS) compared with those with lower scores $(\mathrm{P}<0.001)$. In addition, there were significant differences in event-free survival (EFS) among scoring groups $(\mathrm{P}=0.0059)$. $\mathrm{PV}$ and ET had a better prognosis compared with PMF, although this analysis suggested that PV and ET patients with scores of 4 or 5 may have a poorer prognosis in terms of OS $(\mathrm{P}=0.0052)$ and $\mathrm{EFS}(\mathrm{P}=0.022)$ and should be closely followed up. We observed no significant prognostic effect of the JAK2V167F mutation for OS $(\mathrm{P}=0.28)$ or EFS $(\mathrm{P}=0.17)$. Our results suggested that a simple scoring system based on age, blood cell counts and presence of splenomegaly at diagnosis may be used for the long-term prognosis of MPN patients.
\end{abstract}

Correspondence to: Dr Shinichi Ito, Department of Hematology, Hakodate Municipal Hospital, 1-10-1, Minato-cho, Hakodate, Hokkaido 041-8680, Japan

E-mail: terra-khan@sings.jp

Key words: hematology, myeloproliferative disorders, blood cell count, splenomegaly, prognosis

\section{Introduction}

Philadelphia chromosome-negative myeloproliferative neoplasms (MPNs), including polycythemia vera (PV), essential thrombocytosis (ET) and primary myelofibrosis (PMF), are a group of phenotypically related clonal hematopoietic diseases mainly characterized by the overproduction of blood cells, apart from cytopenia, particularly in PMF (1). During the prolonged clinical course of MPNs, thrombosis, infection due to leukocytopenia and transformation to acute myeloid leukemia (AML) are the main causes of death (2-4).

The acquired Janus kinase 2 (JAK2) V617F mutation is detected in $>95 \%$ of patients with PV and $50-60 \%$ of patients with ET or PMF (5). In JAK2V617F mutation-negative MPNs, other gene mutations, such as those of the myeloproliferative leukemia protein (MPL) and calreticulin (CALR) genes, are often detected (6-9). In particular, it was reported that ET and PMF patients with CALR mutations have a better prognosis compared with patients with JAK2 or MPL mutations $(6,7,9)$. However, the determination of gene mutations is costly and not widely used. Apart from the JAK2V617F mutation, gene mutation tests are not covered by insurance in Japan.

The aim of our study was to determine the prognostic factors obtainable from commonly used information, such as patient characteristics, blood cell count, bone marrow examination and imaging modalities.

\section{Patients and methods}

Patients. We reviewed 71 patients with Philadelphia chromosome-negative MPNs diagnosed at the Hakodate Municipal Hospital (Hakodate, Japan) between April, 2001 and April, 2014. The diagnosis was based on the World Health Organization criteria (10). Patients diagnosed at our department but followed up in other hospitals were excluded from the analysis. This study was approved by the Hakodate Municipal Hospital Institutional Review Board. All the patients provided written informed consent according to the Declaration of Helsinki.

Definition of risk scoring. Abnormal values of white blood cell (WBC) count, hemoglobin (Hb) concentration, 
Table I. Baseline characteristics of all MPN patients $(n=71)$.

\begin{tabular}{|c|c|c|c|c|c|}
\hline \multirow[b]{2}{*}{ Characteristics } & \multicolumn{4}{|c|}{ Types of MPN } & \multirow[b]{2}{*}{ P-value } \\
\hline & $\mathrm{PV}(\mathrm{n}=17)$ & $\mathrm{ET}(\mathrm{n}=34)$ & $\operatorname{PMF}(n=16)$ & MPN, u (n=4) & \\
\hline Median age, years (range) & $62(44-76)$ & $69(16-88)$ & $70(30-81)$ & $75(46-87)$ & 0.40028 \\
\hline Gender, male, n (\%) & $11(65)$ & $14(41)$ & $11(69)$ & $2(50)$ & 0.23711 \\
\hline $\begin{array}{l}\text { Abnormal WBC count, n (\%) } \\
>\text { ULN } \\
<\text { LLN }\end{array}$ & $\begin{array}{l}8(47) \\
8(47) \\
0(0)\end{array}$ & $\begin{array}{l}13(38) \\
12(35) \\
1(3)\end{array}$ & $\begin{aligned} & 10(62) \\
& 9(56) \\
& 1(6)\end{aligned}$ & $\begin{array}{l}4(100) \\
4(100) \\
0(0)\end{array}$ & 0.296929 \\
\hline $\begin{array}{l}\text { Abnormal Hb level, n (\%) } \\
>\text { ULN } \\
<\text { LLN }\end{array}$ & $\begin{array}{l}15(88) \\
15(88) \\
0(0)\end{array}$ & $\begin{array}{l}8(24) \\
1(3) \\
7(21)\end{array}$ & $\begin{aligned} 10 & (62) \\
1 & (6) \\
9 & (56)\end{aligned}$ & $\begin{array}{l}1(25) \\
1(25) \\
0(0)\end{array}$ & $1.51 \mathrm{E}-09$ \\
\hline $\begin{array}{l}\text { Abnormal Hct, n (\%) } \\
>\text { ULN } \\
<\text { LLN }\end{array}$ & $\begin{array}{l}17(100) \\
17(100) \\
0(0)\end{array}$ & $\begin{array}{l}14(41) \\
11(32) \\
3(9)\end{array}$ & $\begin{array}{r}13(81) \\
3(19) \\
10(63)\end{array}$ & $\begin{array}{l}3(75) \\
3(75) \\
0(0)\end{array}$ & $1.98 \mathrm{E}-08$ \\
\hline $\begin{array}{l}\text { Abnormal PLT count, } \mathrm{n}(\%) \\
>\text { ULN } \\
<\text { LLN }\end{array}$ & $\begin{array}{l}9(53) \\
9(53) \\
0(0)\end{array}$ & $\begin{array}{c}34(100) \\
34(100) \\
0(0)\end{array}$ & $\begin{array}{r}13(81) \\
9(56) \\
4(25)\end{array}$ & $\begin{array}{l}3(75) \\
3(75) \\
0(0)\end{array}$ & 0.00013 \\
\hline Splenomegaly, n (\%) & $9(53)$ & $8(24)$ & $11(53)$ & $2(50)$ & 0.018394 \\
\hline Abnormal karyotype, n (\%) & $3(18)$ & $6(18)$ & $7(44)$ & $2(50)$ & 0.176625 \\
\hline $\begin{array}{l}\text { JAK2V617F mutation, n (\%) } \\
\text { Tested } \\
\text { Mutation-positive }\end{array}$ & $\begin{array}{r}13(76) \\
8(62)\end{array}$ & $\begin{array}{l}25(74) \\
17(68)\end{array}$ & $\begin{array}{l}7(44) \\
4(57)\end{array}$ & $\begin{array}{l}2(50) \\
1(50)\end{array}$ & 0.929494 \\
\hline $\begin{array}{l}\text { Follow-up duration, months } \\
\text { Median (range) }\end{array}$ & $43(12-100)$ & $38(2-151)$ & $41(4-105)$ & $31(22-36)$ & 0.10206 \\
\hline
\end{tabular}

Table II. Causes of mortality and events.

\begin{tabular}{lllr}
\hline Causes of mortality & \multicolumn{2}{c}{ Events } \\
\hline Transformation to AML & 3 & Increasing blood cell counts and addition of chemotherapy & 10 \\
Renal failure & 2 & Appearance or aggravation of splenomegaly & 6 \\
Pneumonia & 1 & Complication of myelofibrosis & 3 \\
Hemophagocytic syndrome & 1 & Transformation to AML & 3 \\
Uncontrollable bleeding & 1 & Death unrelated to MPN & 2 \\
due to thrombocytopenia & & Renal failure & 1 \\
Malignant pleural effusion & 1 & Stroke & 1 \\
Stroke & 1 & Hepatic failure (HBV-positive) & \\
Hepatic failure (HBV-positive) & 1 & & \\
Unexpected cardiopulmonary arrest & 1 & &
\end{tabular}

AML, acute myeloid leukemia; HBV, hepatitis B virus; MPD, myeloproliferative neoplasm.

hematocrit (Hct) and platelet (PLT) count were defined as higher than the upper limits of normal values (ULN), or lower than the lower limits of normal values (LLN). Abnormal erythrocytic lineages were reflected in abnormal $\mathrm{Hb}$ and/or Hct values. In addition to the number of abnormal blood cell lineages, one point each was assigned for age $>65$ years and splenomegaly. Each MPN patient was subsequently assigned a score of 1-6.

Cytogenetics and JAK2V617F mutation. For the detection of the JAK2V617F mutation, allele-specific polymerase chain 
A

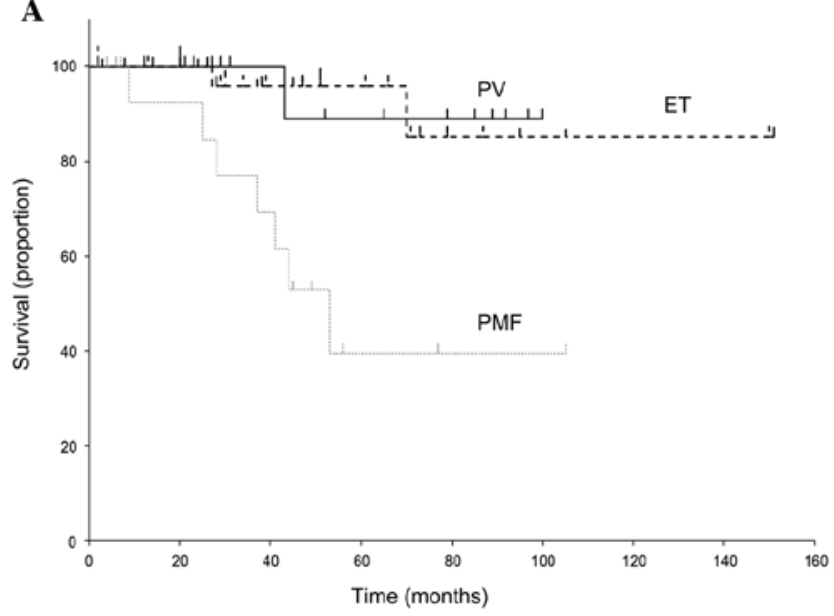

B

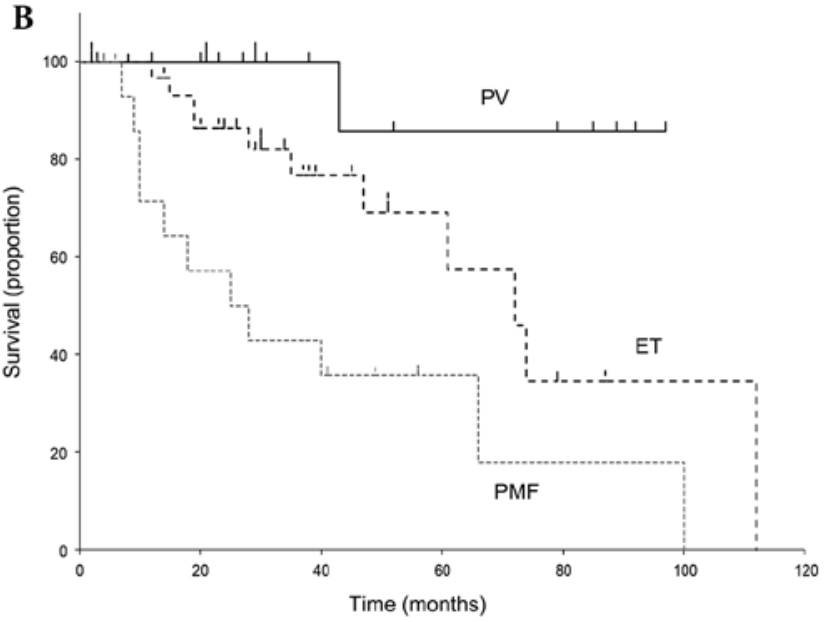

Figure 1. (A) Overall survival curve of the 71 patients stratified by type of MPN (excluding MPN, u). (B) Event-free survival curve of the 71 patients stratified by type of MPN (excluding MPN, u). PV, polycythemia vera; ET, essential thrombocytosis; PMF, primary myelofibrosis; MPN, u, myeloproliferative neoplasm, unclassifiable.

reaction analysis was performed as previously reported (11). We were unable to investigate other JAK2 mutations, as this is not covered by insurance in Japan. In our institute, detection of JAK2V617F mutation became accessible in 2013.

Statistical analysis. The baseline characteristics of the patients were described using median and range, and compared using the median test, $\chi^{2}$ analysis and the Fisher's exact test, as appropriate. Overall survival (OS) was defined as the time between the first patient contact and death or the time of the last follow-up. The endpoint of event-free survival (EFS) was defined as transformation to AML, new appearance or aggravation of splenomegaly, addition of an abnormal karyotype, new complication of MF, increasing blood cell counts that required chemotherapy, thrombosis, or patient death from any cause. OS and EFS were evaluated by the Kaplan-Meier method and Mantel-Cox log-rank tests. For univariate and multivariate analysis, logistic regression was used to investigate the association of baseline characteristics with OS and EFS. Statistical analysis was performed with StatMate V software (ATMS Co., Ltd., Tokyo, Japan). $\mathrm{P}<0.05$ was considered to indicate statistically significant differences.

\section{Results}

Initial characteristics and clinical course. Table I provides a comparative presentation of the clinical and laboratory characteristics of each type of MPN [PV, $n=17$; ET, $n=34 ;$ PMF, $n=16$; and MPN, unclassifiable (u), $n=4]$. Significant differences were observed in $\mathrm{Hb}$, Hct, PLT count and splenomegaly, but not in age, gender distribution, WBC count, abnormal karyotype, or frequency of the JAKV617F mutation.

Causes of death and events. The causes of death and endpoints of EFS are presented in Table II. A total of 3 patients succumbed due to transformation to AML, 2 patients due to renal failure and 1 patient each due to pneumonia, hemophagocytic syndrome, uncontrollable bleeding due to thrombocytopenia, malignant pleural effusion, stroke, hepatic failure due to hepatitis B virus infection and unexpected cardiopulmonary arrest. All these patients had multilineage abnormalities in blood counts. The numbers of events were as follows: Increasing blood cell counts and chemotherapy, $\mathrm{n}=10$; appearance or aggravation of splenomegaly, $n=6$; complications of $M F, n=3$; transformation to AML, $n=3$; and death, $n=4$ ( 2 from renal failure and 1 each from stroke and hepatic failure). Addition of an abnormal karyotype was observed in 1 patient concurrently with complications of MF. Thrombosis was not observed in this analysis.

The median follow-up duration for all MPN patients was 37 months (range, 2-151 months). No significant differences were observed among different types of MPN $(\mathrm{P}=0.10)$.

Association of OS and EFS with type of MPN. The survival curves for each type of MPN (excluding MPN, u) are presented in Fig. 1. The median OS of PV, ET and PMF was 43 (range, 12-100), 38 (range, 2-151) and 41 (range, 4-105) months, respectively. The respective median EFSs were 31 (12-97), 30 (2-112) and 22 (4-100) months. As reported, the OS of PMF was worse compared with that of PV and ET $(P=0.0117)$. Similarly, EFS was significantly difference among the different types of MPN $(\mathrm{P}=0.0210)$.

Logistic regression analysis and prognostic factors for $O S$ and EFS. The prognostic factors for OS and EFS on the univariate and multivariate analysis are summarized in Tables III and IV. On univariate analysis, age $(\mathrm{P}=0.043)$, gender $(\mathrm{P}=0.036)$, number of abnormal cell count lineages $(\mathrm{P}=0.020)$ and splenomegaly $(\mathrm{P}=0.0055)$ were found to be significant prognostic factors for OS. However, for EFS, only the number of abnormal cell lineages $(\mathrm{P}=0.0065)$ was identified as a significant prognostic factor. Our results suggest that abnormal karyotype and JAK2V167F mutation did not significantly affect survival.

On multivariate analysis, a significantly worse overall survival was observed for patients who were elderly $(\mathrm{P}=0.042)$ and had splenomegaly $(\mathrm{P}=0.016)$. A significantly worse EFS was observed with higher numbers of abnormal cell lineages $(\mathrm{P}=0.014)$. 
Table III. Univariate logistic regression analysis of prognostic factors for EFS and OS.

\begin{tabular}{llll}
\hline Factors & Odds ratio & P-value & \\
\hline OS & & & CI \\
Age (>65 years) & 1.07 & 0.043 & $1.00-1.15$ \\
Gender (male) & 0.18 & 0.036 & $0.036-0.90$ \\
No. of abnormal & 3.38 & 0.020 & $1.21-9.44$ \\
blood cell lineages & & & $1.95-48.8$ \\
Splenomegaly & 9.75 & 0.0055 & $0.53-8.76$ \\
Abnormal karyotype & 2.15 & 0.28 & $0.68-5.97$ \\
EFS & & & $0.21-1.92$ \\
Age (>65 years) & 2.02 & 0.42 & $1.32-5.64$ \\
Gender (male) & 0.64 & 0.0065 & $0.62-4.37$ \\
No. of abnormal & 2.73 & 0.32 & $0.38-3.93$ \\
blood cell lineages & & 0.73 & $0.36-5.46$ \\
Splenomegaly & 1.65 & 0.63 & \\
Abnormal karyotype & 1.23 & 1.39 &
\end{tabular}

EFS, event-free survival; OS, overall survival; CI, confidence interval; JAK2, Janus kinase 2 gene.

Table IV. Multivariate logistic regression analysis of prognostic factors for EFS and OS.

\begin{tabular}{|c|c|c|c|}
\hline Factors & Odds ratio & P-value & $95 \% \mathrm{CI}$ \\
\hline \multicolumn{4}{|l|}{ OS } \\
\hline Age (>65 years) & 11.2 & 0.042 & $1.08-117.2$ \\
\hline Gender (male) & 0.28 & 0.21 & $0.037-2.08$ \\
\hline $\begin{array}{l}\text { No. of abnormal } \\
\text { blood cell lineages }\end{array}$ & 2.55 & 0.13 & $0.75-8.67$ \\
\hline Splenomegaly & 11.8 & 0.016 & $1.56-90.0$ \\
\hline Abnormal karyotype & 3.60 & 0.19 & $0.52-24.6$ \\
\hline \multicolumn{4}{|l|}{ EFS } \\
\hline Age (>65 years) & 2.02 & 0.20 & $0.68-5.97$ \\
\hline Gender (male) & 0.64 & 0.42 & $0.21-1.92$ \\
\hline $\begin{array}{l}\text { No. of abnormal } \\
\text { blood cell lineages }\end{array}$ & 2.54 & 0.014 & $1.20-5.36$ \\
\hline Splenomegaly & 1.34 & 0.59 & $0.44-4.05$ \\
\hline Abnormal karyotype & 1.12 & 0.85 & $0.33-3.77$ \\
\hline
\end{tabular}

EFS, event-free survival; OS, overall survival; CI, confidence interval.

Scoring system based on age, number of abnormal blood cell lineages and presence of splenomegaly. According to the previously described risk scoring system based on age, abnormalblood cell lineages and splenomegaly, each patient was assigned a sum score of 1-5 adverse points. The five patient groups were then consolidated into three risk groups based on the margin of intergroup survival differences (Fig. 2) as follows: i) Score 1-2 ( $n=23$; median OS, 45 months; median EFS, 38 months); ii) score 3 ( $n=24$; median OS, 39 months; median EFS, 29.5 months); and iii) score 4-5 (n=24; median OS, 32 months; median EFS, 26.5 months). Significant differences were observed among these three groups in terms of OS $(\mathrm{P}=0.011)$ and EFS ( $\mathrm{P}=0.0059)$.

As illustrated in Fig. 1, PMF was associated with a worse prognosis compared with PV and ET (17). Thus, we created two categories of PV-ET analysis (Fig. 3) and PMF analysis (Fig. 4). All the PV/ET patients belonging to the score 1-2 and 3 groups remained alive during the entire duration of the follow-up, with a median survival of 46 months for the score 1-2 and 29.5 months for the score 3 group. However, 3 patients succumbed to the disease in the score 4-5 group (median survival, 34 months); this group had a significantly poorer 

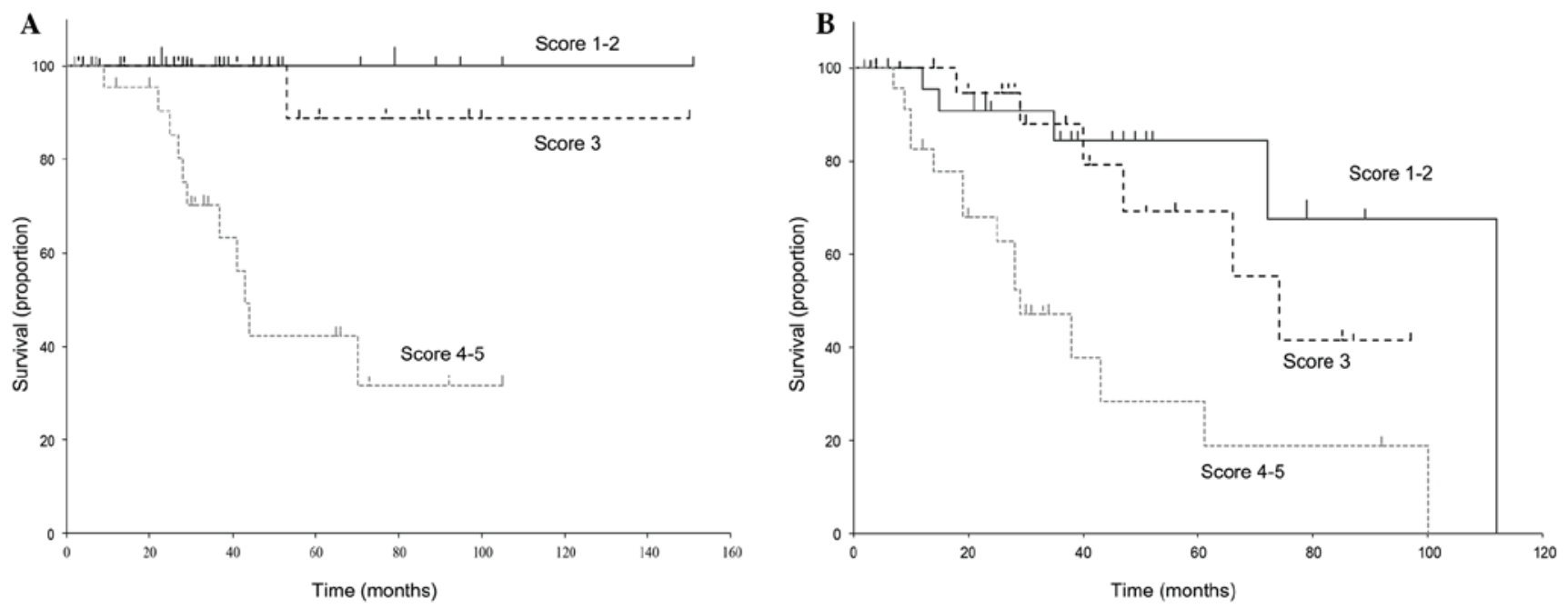

Figure 2. (A) Overall and (B) event-free survival curves of the 71 patients stratified by a risk scoring system based on age, number of abnormal blood cell lineages and splenomegaly at diagnosis.
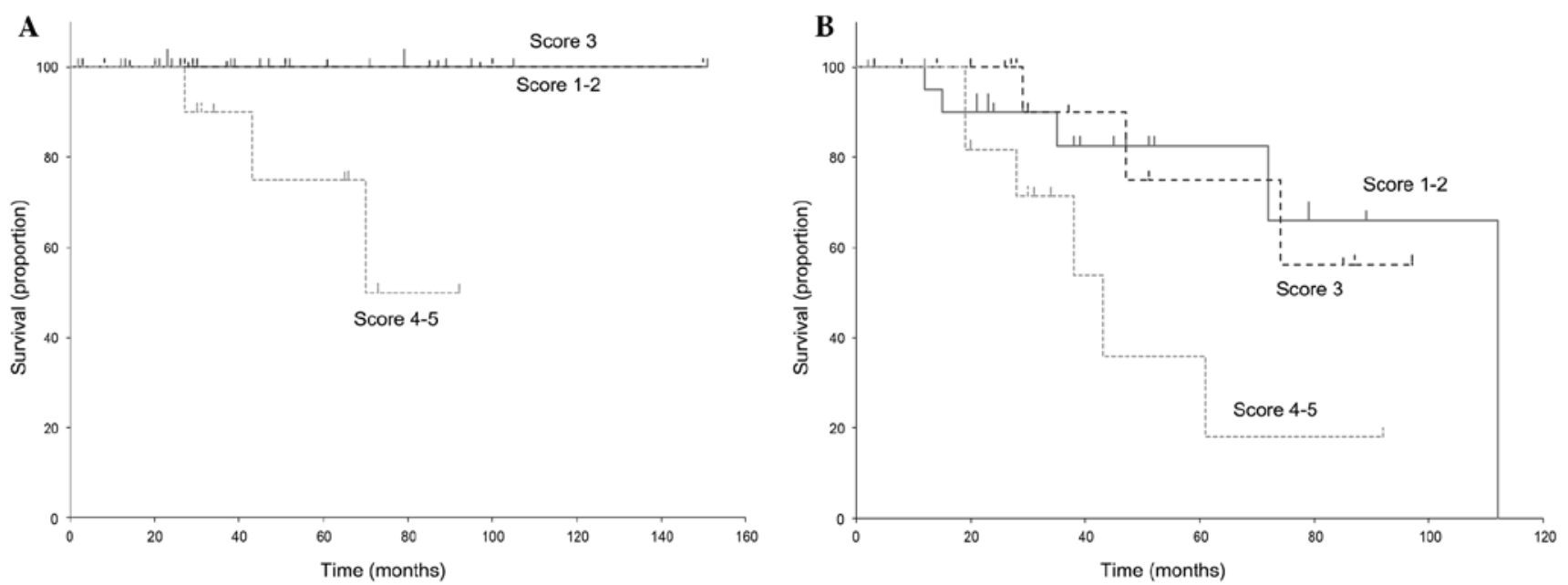

Figure 3. (A) Overall and (B) event-free survival curves of PV and ET patients stratified by a risk scoring system based on age, number of abnormal blood cell lineages and splenomegaly at diagnosis. PV, polycythemia vera; ET, essential thrombocytosis.

prognosis $(\mathrm{P}=0.0053)$. The respective median EFSs of the 3 groups were $38.5,29$ and 30 months. Similarly, the EFS of the score 4-5 group was significantly worse compared with that of the other groups $(\mathrm{P}=0.022)$.

The OS and EFS curves of PMF patients are presented in Fig. 4. Only 2 patients had a score of 1-2, 6 patients had a score of 3 , and 8 patients scored 4-5. No significant differences were observed within each group (OS, $\mathrm{P}=0.177 ; \mathrm{EFS}, \mathrm{P}=0.520)$. However, our results suggested that PMF patients with a score of 4-5 may have a worse outcome compared with the lower scoring groups $(\mathrm{OS}, \mathrm{P}=0.023$ and $\mathrm{EFS}, \mathrm{P}=0.142$ in a statistical analysis of the score 3 vs. the score 4-5 group).

Prognosis and JAK2V617F mutation. A total of 47 patients were tested for the presence of the JAK2V617F mutation. The survival curves are presented in Fig. 5. We observed no statistical association of OS and EFS with the JAK2V617F mutation in MPN patients (OS, $\mathrm{P}=0.281$; $\mathrm{EFS}, \mathrm{P}=0.174)$.

\section{Discussion}

Several studies investigated the prognostic factors for MPNs. In PV, the risk factors of transformation to MF or AML were reported to be advanced age, duration of the disease and leukocytosis at diagnosis (12) and the prognostic factors of ET patients were reported to be advanced age, anemia and thrombocytosis (PLT count $>1,000 \times 10^{9} / 1$ ) (3). In PMF, the International Working Group for Myeloproliferative Neoplasms Research and Treatment propounds the risk stratification categorized by advanced age ( $>65$ years), anemia ( $\mathrm{Hb}<10 \mathrm{gdl}$ ), leukocytosis (leukocyte count $>25 \times 10^{9} / \mathrm{l}$ ), circulating blasts, constitutional symptoms, unfavorable karyotype, thrombocytopenia (PLT count $<100 \times 10^{9} / 1$ ) and required red cell transfusion (DIPSS-plus) $(4,13)$. By contrast, the prognostic factors were evaluated as blood cell count 'outside the normal range', including not only anemia, leukocytosis, and thrombocytopenia, but also polycythemia, leukocytopenia and 

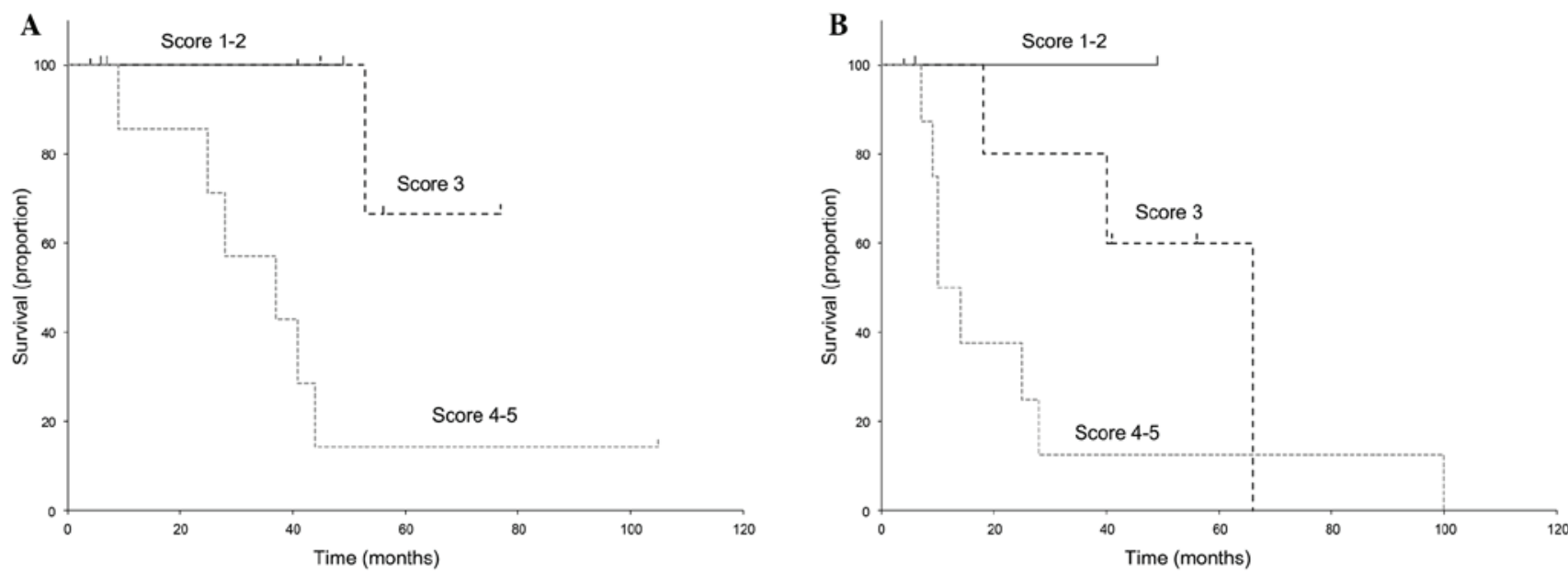

Figure 4. (A) Overall and (B) event-free survival curves of PMF patients stratified by a risk scoring system based on age, number of abnormal blood cell lineages and splenomegaly at diagnosis. PMF, primary myelofibrosis.
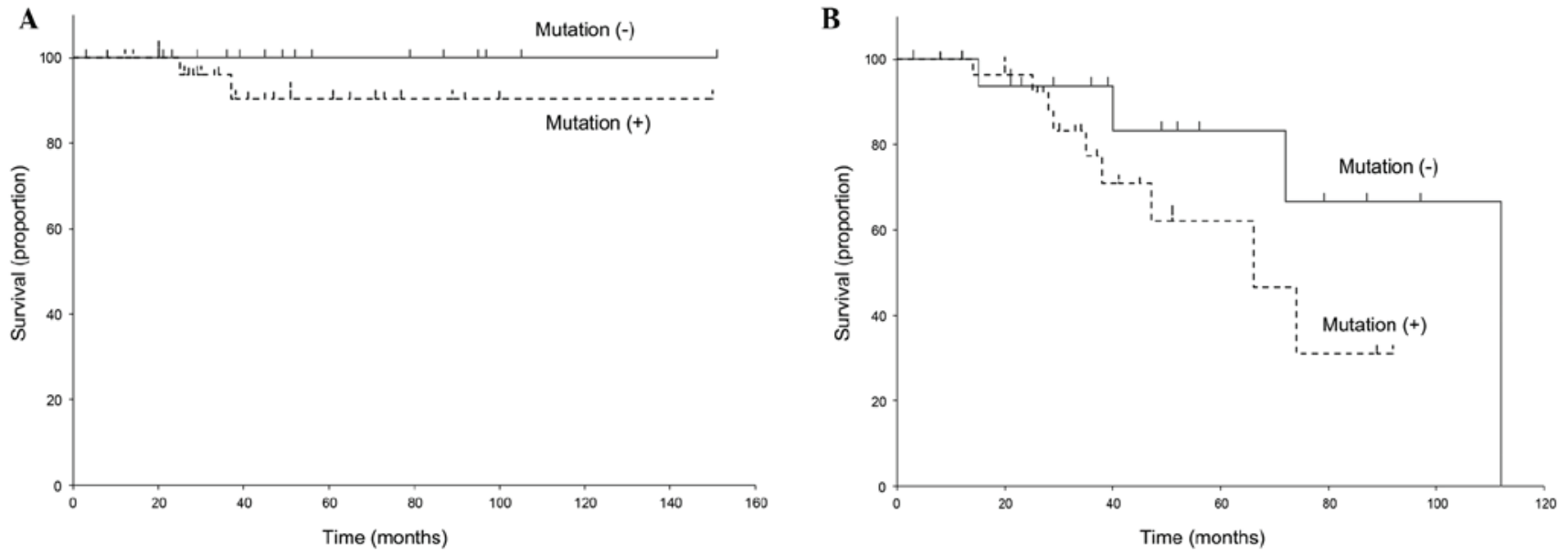

Figure 5. (A) Overall and (B) event-free survival curves of JAK2V617F mutation-examined patients. JAK2, Janus kinase 2 gene.

thrombocytosis. Our study proved that abnormal blood cell count may be a prognostic index, even if the value should be higher than ULN or lower than LLN.

Our results did not confirm the effect of abnormal karyotype on prognosis. Previous studies demonstrated that the prognosis may be poor in PMF patients with an unfavorable karyotype that was defined as complex karyotype or single or double abnormalities, including $+8,-7 / 7 q, i(17 q),-5 / 5 q, 12 p-$, inv(3) or $11 \mathrm{q} 23$ rearrangement $(4,14,15)$. In our study, only 3 patients out of 18 with an abnormal karyotype fall into this unfavorable karyotype category ( 2 patients had trisomy 8 and 1 patient had 11q23 rearrangement); thus, we were unable to analyze the effect of that unfavorable karyotype on the prognosis of MPNs. Gender is not a significant factor affecting the survival of MPN patients according to a number of previous reports $(3,4,13)$. Carobbio et al proved that male patients with ET are at higher risk of venous thrombosis compared with female patients (16). However, our results demonstrated that men had a worse prognosis compared with women in terms of OS.

The tyrosine kinase JAK2 is directly associated with the pathogenesis of MPNs, with the identification of JAK2V617F as a recurring gain-of-function mutation $(17,18)$. Almost all cases with PV, and $~ 50 \%$ of patients with ET and PMF, carry this specific mutation; however, in our results, there was no statistically significant difference in EFS between MPN patients with and those without the JAK2V617F mutation. Similarly, previously published results suggested that the JAK2V617F status did not affect survival in MPNs $(19,20)$. This fact may suggest that the JAK2V617F mutation is a significant underlying cause of MPNs, but additional gene mutations are required to develop MPNs. Uncontrollable increasing blood cell counts, additional $\mathrm{MF}$ and transformation to $\mathrm{AML}$, which are prognostic factors of MPNs, may be the consequences of additional gene mutations. Other types of JAK2 mutations, e.g., JAK2 exon 12 mutations, may be detected in MPNs, particularly PV patients $(6,7,21)$, but it remains unknown whether these JAK2 mutations, with the exception of JAKV617F, affect prognosis. Among a number of gene mutations found in MPN patients, it was recently demonstrated that ET and PMF patients harboring CALR mutations may have a poor prognosis $(6,7,9)$.

The benefits of categorization of MPN patients by our risk scoring are a cost-effective, ubiquitous and useful index 
for general physicians. Apart from JAK2V167F, gene mutation investigation is not covered by insurance in Japan and is only accessible in university hospitals or research institutes. By contrast, we may readily categorize MPN patients using a blood cell counter. Additional methods, such as ultrasonography to evaluate splenomegaly and bone marrow aspiration, are commonly used. These ordinary examinations may be able to identify MPN patients with a poor prognosis. Multilineage blood cell counts may indicate the necessity of consulting with a hematologist.

\section{References}

1. Vardiman JW, Thiele J, Arber DA, Brunning RD, Borowitz MJ, Porwit A, Harris NL, Le Beau MM, Hellström-Lindberg E, Tefferi A, et al: The 2008 revision of the World Health Organization (WHO) classification of myeloid neoplasms and acute leukemia: Rationale and important changes. Blood 114: 937-951, 2009

2. Streiff MB, Smith B and Spivak JL: The diagnosis and management of polycythemia vera in the era since the Polycythemia Vera Study Group: A survey of American Society of Hematology members' practice patterns. Blood 99: 1144-1149, 2002.

3. Tefferi A: Polycythemia vera and essential thrombocythemia: 2013 update on diagnosis, risk-stratification, and management. Am J Hematol 88: 507-516, 2013.

4. Gangat N, Caramazza D, Vaidya R, George G, Begna K, Schwager S, Van Dyke D, Hanson C, Wu W, Pardanani A, et al: DIPSS plus: A refined Dynamic International Prognostic Scoring System for primary myelofibrosis that incorporates prognostic information from karyotype, platelet count, and transfusion status. J Clin Oncol 29: 392-397, 2011

5. Levine RL, Wadleigh M, Cools J, Ebert BL, Wernig G, Huntly BJ, Boggon TJ, Wlodarska I, Clark JJ, Moore S, et al: Activating mutation in the tyrosine kinase JAK2 in polycythemia vera, essential thrombocythemia, and myeloid metaplasia with myelofibrosis. Cancer Cell 7: 387-397, 2005.

6. Rumi E, Pietra D, Ferretti V, Klampfl T, Harutyunyan AS, Milosevic JD, Them NC, Berg T, Elena C, Casetti IC, et al; Associazione Italiana per la Ricerca sul Cancro Gruppo Italiano Malattie Mieloproliferative Investigators: JAK2 or CALR mutation status defines subtypes of essential thrombocythemia with substantially different clinical course and outcomes. Blood 123: 1544-1551, 2014.

7. Rotunno G, Mannarelli C, Guglielmelli P, Pacilli A, Pancrazzi A, Pieri L, Fanelli T, Bosi A and Vannucchi AM; Associazione Italiana per la Ricerca sul Cancro Gruppo Italiano Malattie Mieloproliferative Investigators: Impact of calreticulin mutations on clinical and hematological phenotype and outcome in essential thrombocythemia. Blood 123: 1552-1555, 2014

8. Nangalia J, Massie CE, Baxter EJ, Nice FL, Gundem G, Wedge DC, Avezov E, Li J, Kollmann K, Kent DG, et al: Somatic CALR mutations in myeloproliferative neoplasms with nonmutated JAK2. N Engl J Med 369: 2391-2405, 2013.
9. Klampfl T, Gisslinger H, Harutyunyan AS, Nivarthi H, Rumi E, Milosevic JD, Them NC, Berg T, Gisslinger B, Pietra D, et al: Somatic mutations of calreticulin in myeloproliferative neoplasms. N Engl J Med 369: 2379-2390, 2013.

10. Swerdlow SH, Campo E, Harris NL, Jaffe ES, Pileri SA, Stein H, Thiele J and Vardiman JW (eds): WHO classification of tumours of haematopoietic and lymphoid tissues. In: World Health Organization. 4th edition. IARC Press, Lyon, 2008.

11. Tanaka R, Kuroda J, Stevenson W, Ashihara E, Ishikawa T, Taki T, Kobayashi Y, Kamitsuji Y, Kawata E, TakeuchixM, et al: Fully automated and super-rapid system for the detection of JAK2V617F mutation. Leuk Res 32: 1462-1467, 2008.

12. Marchioli R, Finazzi G, Landolfi R, Kutti J, Gisslinger H, Patrono C, Marilus R, Villegas A, Tognoni G and Barbui T: Vascular and neoplastic risk in a large cohort of patients with polycythemia vera. J Clin Oncol 23: 2224-2232, 2005.

13. Passamonti F, Cervantes F, Vannucchi AM, Morra E, Rumi E, Pereira A, Guglielmelli P, Pungolino E, Caramella M, Maffioli M, et al: A dynamic prognostic model to predict survival in primary myelofibrosis: A study by the IWG-MRT (International Working Group for Myeloproliferative Neoplasms Research and Treatment). Blood 115: 1703-1708, 2010.

14. Hussein K, Pardanani AD, Van Dyke DL, Hanson CA and Tefferi A: International Prognostic Scoring System-independent cytogenetic risk categorization in primary myelofibrosis. Blood 115: 496-499, 2010.

15. Tam CS, Abruzzo LV, Lin KI, Cortes J, Lynn A, Keating MJ, Thomas DA, Pierce S, Kantarjian H and Verstovsek S: The role of cytogenetic abnormalities as a prognostic marker in primary myelofibrosis: Applicability at the time of diagnosis and later during disease course. Blood 113: 4171-4178, 2009.

16. Carobbio A, Thiele J, Passamonti F, Rumi E, Ruggeri M, Rodeghiero F, Randi ML, Bertozzi I, Vannucchi AM, Antonioli E, et al: Risk factors for arterial and venous thrombosis in WHO-defined essential thrombocythemia: An international study of 891 patients. Blood 117: 5857-5859, 2011.

17. Koppikar P and Levine RL: JAK2 and MPL mutations in myeloproliferative neoplasms. Acta Haematol 119: 218-225, 2008.

18. Levine RL and Gilliland DG: Myeloproliferative disorders. Blood 112: 2190-2198, 2008.

19. Thoennissen NH, Krug UO, Lee DH, Kawamata N, Iwanski GB, Lasho T, Weiss T, Nowak D, Koren-Michowitz M, Kato M, et al: Prevalence and prognostic impact of allelic imbalances associated with leukemic transformation of Philadelphia chromosome-negative myeloproliferative neoplasms. Blood 115: 2882-2890, 2010.

20. Cervantes F, Passamonti F and Barosi G: Life expectancy and prognostic factors in the classic BCR/ABL-negative myeloproliferative disorders. Leukemia 22: 905-914, 2008

21. Scott LM, Tong W, Levine RL, Scott MA, Beer PA, Stratton MR, Futreal PA, Erber WN, McMullin MF, Harrison CN, et al: JAK2 exon 12 mutations in polycythemia vera and idiopathic erythrocytosis. N Engl J Med 356: 459-468, 2007. 